\title{
Endoscopic ultrasound-guided fine-needle aspiration of pelvic lesions via the upper and lower gastrointestinal tract approaches
}

\author{
Naoki Mita', Takuji Iwashita ${ }^{*} \mathbb{0}$, Akihiko Senju ${ }^{1}$, Hironao Ichikawa', Yuhei Iwasa', Shinya Uemura', \\ Ichiro Yasuda ${ }^{2}$ and Masahito Shimizu'
}

\begin{abstract}
Background: Combining upper and lower gastrointestinal tract (Gl) approaches allows expansion of endoscopic ultrasound-guided fine-needle aspiration (EUS-FNA) indications for pelvic lesions. The upper Gl approach has been used for pelvic lesions around the level of the aortoiliac bifurcation in our institution. The aim of this study is to evaluate the feasibility and safety of EUS-FNA for pelvic lesions via the upper and lower Gl approaches.
\end{abstract}

Methods: All consecutive patients who underwent EUS-FNA for the pelvic lesion between January 2008 and December 2018 were retrospectively analyzed. Pelvic lesions were defined as lesions located around and below the aortoiliac bifurcation level. The primary outcome was technical success rate, and the secondary outcomes were the diagnostic capability of EUS-FNA for malignancy and the safety.

Results: EUS-FNA for pelvic lesions was performed in 49 patients: upper and lower Gl approaches were used in 28 and 21 patients, respectively. The technical success rates were 91.8\% (45/49) in all patients: 89.3\% (25/28) and 95.2\% (20/21) with the upper and lower Gl approaches, respectively. Among patients who achieved technical success, the diagnostic accuracy for malignancy was $97.8 \%(44 / 45)$ in all patients: 100\% (25/25) and 95.0\% (19/20) with the upper and lower Gl approaches, respectively. One (2.0\%) patient developed an adverse event of sigmoid colon perforation.

Conclusions: EUS-FNA for pelvic lesions via the upper and lower Gl approaches was a safe, feasible, and effective method, although careful endoscopic manipulation is required to avoid perforation, especially with the lower Gl approach. Further large-scale, well-designed studies are needed to validate our findings.

Keywords: Pelvic lesion, Malignant lymphoma, Fine needle biopsy

\section{Background}

Endoscopic ultrasound-guided fine-needle aspiration (EUS-FNA) has been a standard technique to obtain pathological specimens from lesions around the upper gastrointestinal tract (GI)[1], such as pancreatic tumors $[2,3]$, upper abdominal lymph nodes [4, 5], mediastinal masses [6], or upper gastrointestinal submucosal tumors

\footnotetext{
*Correspondence: takuji@w7.dion.ne.jp

1 First Department of Internal Medicine, Gifu University Hospital, 1-1 Yanagido, Gifu 501-1194, Japan

Full list of author information is available at the end of the article
}

[7, 8]. However, the feasibility and safety of EUS-FNA for pelvic lesions have not been well studied, although EUS-FNA for pelvic lesions via the lower GI approach was reported in several studies, including one systematic review and meta-analysis [9-11], in which target lesions were limited around the rectal or perirectal area. As our previously reported case series [12], the lesions around the level of the aortoiliac and internal-external iliac bifurcation could be approached with the upper GI, whereas other pelvic lesions located below that level could be approached with the lower GI. In our institution, the initial approach method during EUS-FNA, 
either the upper or lower GI, has been decided based on the above criteria.

Therefore, we conducted this retrospective study to evaluate the feasibility, efficacy, and safety of EUS-FNA for pelvic lesions via the upper or lower GI approach and the reference method to decide the approach route, either the upper or lower GI.

\section{Methods}

\section{Study design and patient selection}

This was a retrospective study conducted at a single academic care center (Gifu University Hospital). The database analysis including all EUS-FNA procedures between January 2008 and December 2018 was performed to identify patients who underwent EUS-FNA for pelvic lesions. Pelvic lesions were defined as lesions located in the pelvic area around and below the aortoiliac bifurcation level on computed tomography (CT). This study had no exclusion criteria. All patients provided written informed consent for EUS-FNA. The study was conducted in accordance with the human and ethical principles of research set forth by the Helsinki guidelines. The study protocol was approved by the Institutional Review Board of Gifu University Hospital.

\section{Selection of approach route and EUS-FNA techniques}

The location of lesions was evaluated by CT before EUSFNA. The approach route via either the upper or lower GI for EUS-FNA was decided based on the location of the lesion on CT. The selection reference was as follows: the upper GI approach for pelvic lesions located around the aortoiliac and internal-external iliac bifurcation levels and the lower GI approach for those around the rectum and sigmoid colon. All endoscopic ultrasound-guided (EUS) procedures were performed using an electronic linear scanning video echoendoscope with an oblique forward optical view (GF-UC240P-AL5 or GF-UCT260; Olympus, Tokyo, Japan).

In the upper GI approach, EUS scanning for lesions was first attempted from the stomach followed by the second portion of the duodenum (D2) with the pulling position as that used in endoscopic retrograde cholangiopancreatography. In the EUS scanning from D2, the aortoiliac bifurcation was visualized with further insertion of the EUS scope into the deep portion of D2 with keeping the longitudinal view of the aorta. In patients with lesions that can be visualized from both the stomach and D2, fine-needle aspiration (FNA) was performed from either approach route per the operator's decision for a more reliable and safe EUS-FNA. In the lower GI approach, patients underwent screening colonoscopy to evaluate possible underlying colonic diseases, such as advanced cancer, which could be an obstacle for EUS-FNA. The target lesion was visualized using the surrounding organs, such as the urinary bladder, prostate, or uterus, as the landmark, and EUS-FNA was performed from the rectum or sigmoid colon. Prophylactic antibiotics were administered at the operator's discretion after performing EUS-FNA via the lower GI approach.

EUS-FNA was attempted using FNA or FNB needles. The used FNA needles were a 19-gauge needle (Echotip, Cook, Winston-Salem, NC, USA; Expect, Boston Scientific, USA; EZ shot 3 plus, Olympus, Tokyo, Japan), 22-gauge needle (SonoTip Pro Control, Medi-Globe $\mathrm{GmbH}$, Germany), or 25-gauge needle (Echotip; Cook, Winston-Salem, NC, USA). The FNB needles were a 19-gauge needle (Acquire, Boston Scientific) or 22-gauge needle (Acquire, Boston Scientific). EUS-FNA was performed mainly using a 10 or $20 \mathrm{cc}$ negative pressure or a slow-pull technique to apply a minimal negative pressure. The obtained specimen was macroscopically evaluated, and whitish or yellowish pieces of tissue were fixed in formalin for histological evaluation, as we previously reported [13]. Then, a smear was made on the remaining specimen for cytologic evaluation and fixed in absolute alcohol. Rapid on-site cytologic evaluation was unavailable in our hospital. EUS-FNA was performed on an outpatient basis. After the FNA, patients were monitored for immediate adverse events (AEs) in the recovery room at least for $2 \mathrm{~h}$. Additional examinations, such as blood tests or CT, were performed as necessary. The AEs were evaluated according to the American Society for Gastrointestinal Endoscopy workshop report [14].

\section{Study outcomes, reference methods for the final diagnosis, and statistical analysis}

The primary outcome was the technical success rate of EUS-FNA for pelvic lesions with our reference method to decide the approach route, either via the upper or lower GI. Secondary outcomes were diagnostic capability of EUS-FNA and safety. The final diagnosis was obtained using the following references: (1) surgical diagnosis based on the resected specimen, including autopsy findings; (2) positive FNA diagnosis for malignancy with a compatible clinical course; (3) negative FNA diagnosis for malignancy with a lack of deterioration or spontaneous resolution with a minimal clinical follow-up time of 6 months; or (4) diagnosis for benign disease based on the imaging findings with absence of progression with a minimal clinical follow-up time of 12 months; (5) diagnosis for malignant disease based on the specimen which obtained by the method other than EUS-FNA or surgery. The technical success was defined as the successful completion of EUS-FNA for the targeted lesion. Continuous variables are presented as median and range. The outcome parameters were calculated with $95 \%$ confidence 
interval (95\% CI). All statistical analyses were performed using JMP software, version 14.0.0 (SAS Institute Inc., Cary, NC, USA).

\section{Results}

\section{Patient and lesion characteristics}

Forty-nine patients underwent EUS-FNA for pelvic lesions at our institution from January 2008 to December 2018; 28 via the upper GI approach and 21 via the lower GI approach. Basic characteristics of patients are shown in Table 1.

\section{Final diagnosis}

The final diagnoses in the upper GI group were malignancy in 24 patients (85.7\%)-malignant lymphoma in 19 , lymph node metastasis of malignant tumor in 4 (ovarian cancer in 2, gallbladder cancer in 1 renal cancer in 1),

Table 1 Patient and lesion characteristics

\begin{tabular}{llll}
\hline & Overall & Upper GI & Lower GI \\
\hline Number of patients, $\mathrm{n}$ & 49 & 28 & 21 \\
Age, y.o., median (range) & $69(32-87)$ & $68(32-87)$ & $72(48-83)$ \\
Gender, male/female. $\mathrm{n}$ & $28 / 21$ & $12 / 16$ & $16 / 5$ \\
Size of lesions, mm, median & $40(13-135)$ & $26(32-87)$ & $58(13-135)$ \\
$\quad$ (range) & & & \\
Target lesions, n (\%) & $33(67.3)$ & $23(82.1)$ & $10(47.6)$ \\
$\quad$ Pelvic LN & $7(14.3)$ & $2(7.1)$ & $5(23.8)$ \\
Pelvic mass & $3(6.1)$ & $3(10.7)$ & - \\
$\quad$ Retroperitoneal mass & $6(12.2)$ & - & $6(28.6)$ \\
$\quad$ Submucosal tumor & & & \\
\hline
\end{tabular}

$\mathrm{LN}$, lymph node; $\mathrm{Gl}$, gastrointestinal tract and carcinoma of unknown primary cancer in 1 . In the remaining 4 patients (14.3\%), the final diagnoses were benign-retroperitoneal fibrosis in 3 and lipoma in 1 . The final diagnoses in the lower GI group were malignancy in 18 patients (85.7\%)-malignant lymphoma in 6 , lymph node metastasis of malignant tumor in 5 (bladder cancer recurrence after surgery in 2, rectal cancer recurrence after endoscopic treatment in 2, gallbladder cancer in 1), gastrointestinal stromal tumor in 4, carcinoma of unknown primary in 1, peritoneal mesothelioma in 1, and rectal invasion of bladder cancer in 1 . In the remaining 3 patients (14.3\%), the final diagnoses were benign - schwannoma in 1, Castleman disease in 1, and nonspecific lymphadenopathy in 1 . The final diagnoses were obtained based on the surgical pathology in 12 patients, EUS-FNA results with the clinical course and median follow-up period of 27.2 (range, 6.3-103.3) months in 35 patients, the result of mucosal biopsy of the small intestinal lesion during double-balloon enteroscopy in 1 patient, and the imaging findings with the clinical course and follow up period of 41.3 months in 1 patient (Table 2).

\section{Technical performance}

The technical success rates were $91.8 \%(45 / 49)$ in overall patients-89.3\% (25/28) and 95.2\% (20/21) with the upper and lower GI approaches, respectively. The FNA was unsuccessful via the upper GI approach because of the existence of vessels in the puncture route in 2 patients ( 1 in the aorta and 1 in the inferior vena cava), and the lesion was not detected in 1 patient via the upper GI approach. In the lower GI approach, FNA failed in 1 patient in whom the procedure was complicated by

Table 2 Final diagnoses of the patients with pelvic lesions who underwent EUS-FNA

\begin{tabular}{llll}
\hline & $\begin{array}{l}\text { Overall } \\
\mathbf{n = 4 9}\end{array}$ & Upper GI $\mathbf{n = 2 8}$ & Lower GI $\mathbf{n = 2 1}$ \\
\hline Malignant diseases, $\mathrm{n}(\%)$ & $42(85.7)$ & $24(85.7)$ & $18(85.7)$ \\
Malignant lymphoma & $25(51.0)$ & $19(67.9)$ & $6(28.6)$ \\
LN metastasis of malignant tumor & $9(18.4)$ & $4(14.3)$ & $5(23.8)$ \\
Carcinoma of unknown primary & $2(4.1)$ & $1(3.6)$ & $1(4.8)$ \\
Gastrointestinal stromal tumor & $4(8.2)$ & - & $4(19.0)$ \\
Peritoneal mesothelioma & $1(2.0)$ & - & $1(4.8)$ \\
Rectal invasion of bladder cancer & $1(2.0)$ & $4(14.3)$ & $1(4.8)$ \\
Benign diseases, $n$ (\%) & $7(14.3)$ & $3(10.7)$ & $3(14.3)$ \\
Retroperitoneal fibrosis & $3(61.2)$ & $1(3.6)$ & - \\
Lipoma & $1(2.0)$ & - & - \\
Schwannoma & $1(2.0)$ & - & $1(4.8)$ \\
Castleman disease & $1(2.0)$ & - & $1(4.8)$ \\
Non-specific lymphadenopathy & $1(2.0)$ & - & $1(4.8)$
\end{tabular}


sigmoid colon perforation during the scope insertion. Emergent surgery was required in this patient. Among these 4 patients in whom FNA was unsuccessful, the final diagnoses were obtained based on the surgical pathology in 3 patients (renal cell carcinoma metastasis in 1, retroperitoneal fibrosis 1 , and nonspecific lymphadenopathy in 1). In the remaining 1 patient, further imaging studies including $\mathrm{CT}$, magnetic resonance imaging (MRI), and positron emission tomography CT (PET-CT) indicated suspicious of lipoma, and follow-up imaging studies showed no progression for 41.4 months. Regarding the type of needles, we used a 19-gauge FNA needle in 36 cases, 22-gauge FNA needle in 2 case, 25-gauge FNA needle in 1 case, 19-gauge FNB needle in 1 case and 22 -gauge FNB needle in 5 cases. No AEs were observed, except for one, sigmoid colon perforation. Therefore, the $\mathrm{AE}$ rate was $2.0 \%(1 / 49)$. The location of the target lesions for EUS-FNA and the feasibility of EUS-FNA are shown in Fig. 1 (Table 3).

\section{Diagnostic capability of EUS-FNA}

Among patients who achieved technical success with EUS-FNA, the histological evaluation was feasible in 97.8\% (44/45), although the cytological material was obtained in all patients. The overall sensitivity, specificity, positive predictive value, negative predictive value, and accuracy of EUS-FNA for malignancy were $97.6 \%$ (40/41; 95\% CI 87.4-99.6\%), 100\% (4/4; 95\% CI 51.0100\%), $100 \%$ (40/40; 95\% CI 91.2-100\%), 80.0\% (4/5; 95\% CI $37.6-96.4 \%)$, and $97.8 \%$ (44/45; 95\% CI 88.4-99.6\%), respectively (Table 4). The histological and cytological diagnostic capabilities for malignancy are shown in Tables 5 and Table 6 . In 1 patient with false-negative FNA result, we performed double-balloon endoscopy because the wall thickening of the small intestine was detected by CT imaging. And then, the final diagnosis of malignant lymphoma was obtained with mucosal biopsy of the small intestinal lesion.

\section{Discussion}

The reference method to decide an approach route, either with the upper GI or lower GI, during EUS-FNA for pelvic lesions was evaluated as the technical success in this study. The upper GI approach was selected for pelvic lesions located around the aortoiliac and internal-external iliac bifurcation levels and the lower GI approach was chosen for those located below the level of the internal-external iliac bifurcation. The technical success rates in this study were considered as relatively high and were $91.8 \%(45 / 49)$ in overall-89.3\% (25/28) with the upper GI approach and $95.2 \%(20 / 21)$ with the lower GI approaches. The EUS-FNA failed in 2 of 4 patients because of interposing large vessels on the puncture line.
Unnecessary procedures can be avoided if large vessel disruption during EUS-FNA can be estimated based on CT findings; however, the estimation could be difficult because the intestines are movable during the insertion of EUS, which change the positional relation between the lesion and the scope. Considering the high technical success rate with our approach method and the difficulty in estimating the interposing vessels during FNA, our determination method of the approach route in EUS-FNA for pelvic lesions can be considered appropriate.

The accuracy of EUS-FNA has been reported as $96 \%$ in pancreatic lesions $[2,15], 87.5 \%-98 \%$ in upper abdominal lymph nodes $[4,16]$, and $70 \%-90 \%$ in upper gastrointestinal submucosal lesions [17] in previous studies. Among patients who achieved a technical success with EUS-FNA in this study, the overall accuracy for malignancy with EUS-FNA for pelvic lesions was $97.8 \%$ (44/45), which was comparable to the these reported diagnostic capability. In addition, the 19-gauge needle was most frequently used for FNA in this study, which might contribute to the high histological specimen acquisition rate (97.8\%) and high diagnostic capability since almost half of the final diagnosis in our present study was malignant lymphoma which requires a histological analysis including immune histochemical staining $[18,19]$. Large-bore needles generally compromise maneuverability because of its rigidity and stiffness, making the puncture difficult during EUS-FNA, especially via the transduodenal approach. Our high feasibility might be not applicable for other centers, considering our extensive experience with EUS-FNA using a 19-gauge needle. Actually, Attili et al. reported that the histological sample acquisition rate and overall diagnostic accuracy of transduodenal EUS-FNB using 19-gauge needle as only $76.8 \%$ and $73.6 \%$, respectively[20]. Recently, new fine-needle biopsy (FNB) needles have been developed; they have been reported to have excellent tissue acquisition and histological diagnostic rates, even with a smaller gauge needle size[21-24]. Therefore, the size and type of FNA needle should be chosen considering the location and shape of the EUS scope, lesion size, and operator's experience.

Regarding the safety of EUS-FNA for the pelvic lesion via the upper GI, although no AEs were recognized in this study, the echoendoscope has to be pushed downward against the duodenal or gastric wall to visualize the pelvic lesion, which might increase the risk of perforation or bleeding. The operator should be cautious of not using too much pushing force to visualize the lesions. In a systematic review and meta-analysis of EUS-FNA via the lower GI approach for pelvic lesions conducted by Han et al. [9], which included 10 studies with a total of 236 cases, AEs occurred in 1.7\% (4/236) of cases and were 2 cases of abscesses after EUS-FNA for cystic lesions, 1 
a
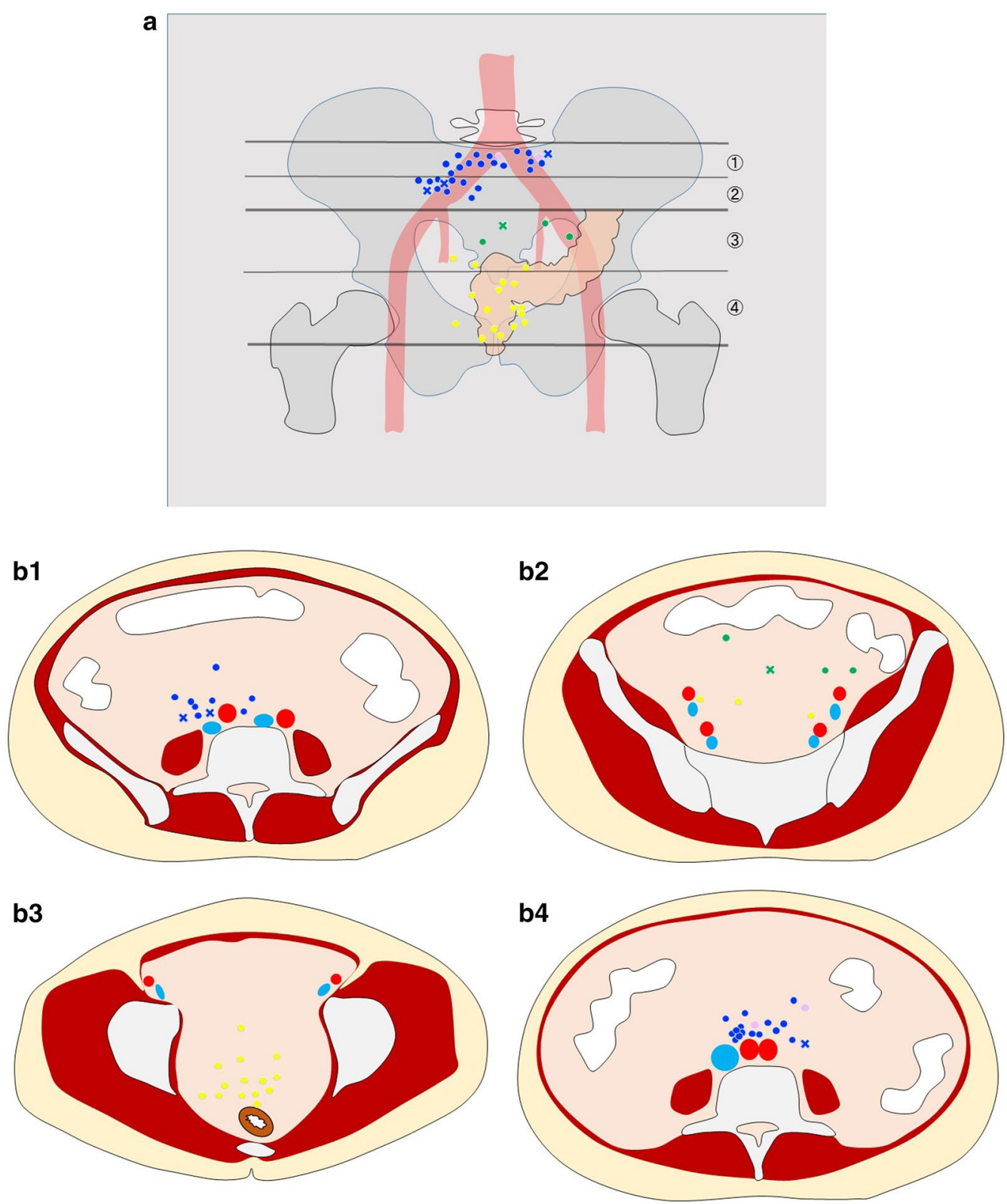

Fig. 1 The location of the lesions, access route, and feasibility of endoscopic ultrasound-guided fine-needle aspiration. A The pelvic cavity was divided into four levels - the aortoiliac bifurcation, internal-external iliac artery bifurcation, sigmoid colon, and rectum. Circle mark indicates successful puncture, although cross mark is unsuccessful puncture. Color indicates puncture sight as following: blue, the second portion of the duodenum; pink, stomach; green, sigmoid colon; yellow, rectum. B1 Axial image of the aorto-iliac bifurcation level. B2 Axial image of the internalexternal iliac artery bifurcation level. B3 Axial image of the sigmoid colon level. B4 Axial image of the rectum level

case of gross hematuria and 1 case of hemorrhage. They concluded EUS-FNA via the lower GI for pelvic lesions is a safe procedure with low AE rate, although we think that indication of EUS-FNA for cystic pelvic mass should be considered carefully. In our study, only 1 patient developed an $\mathrm{AE}$ of sigmoid colon perforation during the EUS-FNA via the lower GI. Considering the limited angulation of a convex-type EUS with oblique viewing, deep insertion of the EUS scope into the sigmoid colon is challenging and requires careful maneuver of the scope to minimize the risk of preformation. Recently, forwardviewing EUS (FV-EUS) having forward optical view and wider scope angulation has been developed; they can be theoretically used as a regular colonoscope[25]. In a study by Thinrungroj et al., EUS-FNA using FV-EUS and fluoroscopy via the lower GI approach, including the 
Table 3 Procedure details and data related EUS-FNA

\begin{tabular}{|c|c|c|c|}
\hline & $\begin{array}{l}\text { Overall } \\
n=49\end{array}$ & $\begin{array}{l}\text { Upper GI } \\
\mathrm{n}=28\end{array}$ & $\begin{array}{l}\text { Lower } \mathrm{Gl} \\
\mathrm{n}=21\end{array}$ \\
\hline Technical success rate of EUS-FNA, n (\%) & $45(91.8)$ & $25(89.3)$ & $20(95.2)$ \\
\hline Reasons for unsuccessful cases, n & & $\begin{array}{l}\text { Existence of vessels in the puncture } \\
\text { route, } 2 \\
\text { The lesion was not detected, } 1\end{array}$ & Sigmoid colon perforation, 1 \\
\hline \multicolumn{4}{|l|}{ Type of needle, n (\%) } \\
\hline 19-gauge FNA needle & $36(73.5)$ & $21(75.0)$ & $15(71.4)$ \\
\hline 22-gauge FNA needle & $2(4.1)$ & $1(3.6)$ & $1(4.8)$ \\
\hline 25-gauge FNA needle & $1(2.0)$ & $1(3.6)$ & - \\
\hline 19-gauge FNB needle & $1(2.0)$ & - & $1(4.8)$ \\
\hline 22-gauge FNB needle & $5(10.2)$ & $2(7.1)$ & $3(14.3)$ \\
\hline Puncture site, n (\%) & & $\begin{array}{l}\text { Duodenum, } 23 \text { (82.1) } \\
\text { Stomach, } 2 \text { (7.1) }\end{array}$ & $\begin{array}{l}\text { Rectum, } 17 \text { (81.0) } \\
\text { Sigmoid colon, } 3 \text { (14.3) }\end{array}$ \\
\hline The number of passes, $n$, median (IQR) & $3(2-3)$ & $3(2-3)$ & $3(2-3)$ \\
\hline Adverse event, n (\%) & $1(4.8)$ & - & Perforation, 1 (4.8) \\
\hline
\end{tabular}

EUS-FNA, endoscopic ultrasound-guided fine needle aspiration; Gl, gastrointestinal tract; FNB, fine needle biopsy; IQR, interquartile range

Table 4 The overall diagnostic capability for malignancy in EUS-FNA for pelvic lesions

\begin{tabular}{lrrr}
\hline & \multicolumn{1}{l}{$\begin{array}{l}\text { All patients } \\
\text { \% (n, 95\%Cl) }\end{array}$} & \multicolumn{1}{c}{$\begin{array}{l}\text { Upper GI } \\
\text { \% (n, 95\%Cl) }\end{array}$} & \multicolumn{1}{c}{$\begin{array}{l}\text { Lower Gl } \\
\text { \% (n, 95\%Cl) }\end{array}$} \\
\hline Sensitivity & $97.6(40 / 41,87.4-99.6)$ & $100(23 / 23,85.7-100)$ & $94.4(17 / 18,74.2-99.0)$ \\
Specificity & $100(4 / 4,51.0-100)$ & $100(2 / 2,34.2-100)$ & $100(2 / 2,34.2-100)$ \\
PPV & $100(40 / 40,91.2-100)$ & $100(23 / 23,85.7-100)$ & $100(17 / 17,81.2-100)$ \\
NPV & $80.0(4 / 5,37.6-96.4)$ & $100(2 / 2,34.2-100)$ & $66.7(2 / 3,20.8-93.9)$ \\
Accuracy & $97.8(44 / 45,88.4-99.6)$ & $100(25 / 25,86.7-100)$ & $95.0(19 / 20,76.4-99.1)$
\end{tabular}

EUS-FNA, endoscopic ultrasound-guided fine needle aspiration; Gl, gastrointestinal tract; Cl confidence interval; PPV, positive predictive value; NPV, negative predictive value

Table5 The histological diagnostic capability for malignancy in EUS-FNA for pelvic lesions

\begin{tabular}{lrrr}
\hline & \multicolumn{1}{c}{$\begin{array}{l}\text { All patients } \\
\text { \% (n, 95\%Cl) }\end{array}$} & \multicolumn{1}{l}{$\begin{array}{l}\text { Upper Gl } \\
\text { \% (n, 95\%Cl) }\end{array}$} \\
\hline Sensitivity & $97.5(39 / 40,87.1-99.6)$ & $100(23 / 23,85.7-100)$ \\
Specificity & $100(4 / 4,51.0-100)$ & $100(2 / 2,34.2-100)$ \\
PPV & $100(39 / 39,91.0-100)$ & $100(23 / 23,85.7-100)$ & $100(2 / 2,34.2-100)$ \\
NPV & $80.0(4 / 5,37.6-96.4)$ & $100(2 / 2,34.2-100)$ & $100(16 / 16,80.6-100)$ \\
Accuracy & $97.7(43 / 44,88.2-99.6)$ & $100(25 / 25,86.7-100)$ \\
\hline
\end{tabular}

EUS-FNA, endoscopic ultrasound-guided fine needle aspiration; Gl, gastrointestinal tract; Cl confidence interval; PPV, positive predictive value; NPV, negative predictive value

deep colon approach, was successfully performed in 13 patients without any AEs [26]. The authors concluded that FV-EUS under fluoroscopy guidance might be an easy, safe, and effective technique for transcolonic EUSFNA. FV-EUS for pelvic lesions can expand the indication of EUS-FNA for pelvic lesions via the lower GI approach and improve the safety especially during the scope insertion.
This study has several limitations. A retrospective study design in a single center with a small sample size might cause biases in the patient selection and external validity of the procedure. A retrospective study design also did not allow to include all patients who had pelvic lesions on imaging studies. The wide period of inclusion and the use both of FNA and FNB needle might cause inconsistency of procedures. The final diagnoses were determined 
Table6 The cytological diagnostic capability for malignancy in EUS-FNA for pelvic lesions

\begin{tabular}{|c|c|c|c|}
\hline & $\begin{array}{l}\text { All patients } \\
\%(n, 95 \% C l)\end{array}$ & $\begin{array}{l}\text { Upper GI } \\
\%(n, 95 \% C l)\end{array}$ & $\begin{array}{l}\text { Lower GI } \\
\%(n, 95 \% C I)\end{array}$ \\
\hline Sensitivity & $82.9(34 / 41,68.7-91.5)$ & $78.3(18 / 23,58.1-90.3)$ & $88.9(16 / 18,67.2-96.9)$ \\
\hline Specificity & $75.0(3 / 4,30.1-95.4)$ & $100(2 / 2,34.2-100)$ & $50.0(1 / 2,9.5-90.5)$ \\
\hline PPV & $97.1(34 / 35,85.5-99.5)$ & $100(18 / 18,82.4-100)$ & $94.1(16 / 17,73.0-99.0)$ \\
\hline NPV & $30.0(3 / 10,10.8-60.3)$ & $28.6(2 / 7,8.2-64.1)$ & $33.3(1 / 3,6.1-79.2)$ \\
\hline Accuracy & $82.2(37 / 45,68.7-90.7)$ & $80.0(20 / 25,60.9-91.1)$ & $85.0(17 / 20,64.0-94.8)$ \\
\hline
\end{tabular}

EUS-FNA, endoscopic ultrasound-guided fine needle aspiration; GI, gastrointestinal tract; Cl confidence interval; PPV, positive predictive value; NPV, negative predictive value

according to both surgical and FNA results, which might cause misdiagnosis in indolent tumors, even with a minimal follow-up period of $>6$ months.

\section{Conclusions}

EUS-FNA for pelvic lesions via the upper and lower GI approaches is a feasible, safe, and reliable procedure, and the internal-external iliac artery bifurcation level can be a good indicator to decide the approach route, either via the upper or lower GI. Larger scale multicenter studies are required to validate the feasibility and safety of EUS-FNA for pelvic lesions and our approach for pelvic lesions with respect to selection of the upper or lower GI approaches.

\section{Abbreviations \\ EUS-FNA: Endoscopic ultrasound-guided fine needle aspiration; GI: Gastroin- testinal tract; D2: 2nd portion of the duodenum; Cl: Confidence interval; MRI: Magnetic resonance imaging; PET-CT: Positron emission tomography-CT; FV-EUS: Forward-viewing therapeutic linear echoendoscope.}

\section{Acknowledgements}

Not applicable.

\section{Author's contributions}

$\mathrm{NM}$ and TI wrote the manuscript. NM, TI, AS, HI, YI, SU, MS managed the patients. TI took the correspondence. All authors read and approved the final manuscript.

\section{Funding}

No funding was provided for this study.

\section{Availability of data and materials}

All data generated or analyzed during this study are included in the tables. The study data is available from the corresponding author upon reasonable request.

\section{Ethics approval and consent participate}

The study protocol was approved by the Institutional Review Board of Gifu University Hospital. All patients provided written informed consent for EUS-FNA.

\section{Consent for publication}

Not applicable.

\section{Competing interests}

The authors declare that they have no competing interests.

\section{Author details}

${ }^{1}$ First Department of Internal Medicine, Gifu University Hospital, 1-1 Yanagido, Gifu 501-1194, Japan. ${ }^{2}$ Third Department of Internal Medicine, University of Toyama Hospital, Toyama, Japan.

Received: 13 July 2020 Accepted: 15 December 2020

Published online: 06 January 2021

\section{References}

1. Cazacu IM, Alexandra A, Chavez L, Saftoiu A, Vilmann P, Bhutani MS. A quarter century of EUS-FNA : progress, milestones, and future directions. Endosc Ultrasound. 2018;7:141-60.

2. Yoshinaga S, Itoi T, Yamao K, Yasuda I, Irisawa A, Imaoka H, Tsuchiya T, Doi S, Yamabe A, Murakami Y, et al. Safety and efficacy of endoscopic ultrasound-guided fine needle aspiration for pancreatic masses: a prospective multicenter study. Dig Endosc. 2020;32:114-26.

3. Yoon SB, Moon SH, Song TJ, Kim JH, Kim MH. Endoscopic ultrasoundguided fine needle aspiration versus biopsy for diagnosis of autoimmune pancreatitis: a systematic review and comparative meta-analysis. Dig Endosc. 2020. https://doi.org/10.1111/den.13866.

4. Iwashita T, Yasuda I, Doi S, Nakashima M, Tsurumi H, Hirose Y, Takami T, Enya M, Mukai T, Ohnishi T, et al. Endoscopic ultrasound-guided fineneedle aspiration in patients with lymphadenopathy suspected of recurrent malignancy after curative treatment. J Gastroenterol. 2009;44:190-6.

5. Chen L, Li Y, Gao X, Lin S, He L, Luo G, Li J, Huang C, Wang G, Yang Q, Shan $H$. High diagnostic accuracy and safety of endoscopic ultrasound-guided fine-needle aspiration in malignant lymph nodes: a systematic review and meta-analysis. Dig Dis Sci. 2020. https://doi.org/10.1007/s10620-02006554-2.

6. Yasuda I, Kato T, Asano F, Okubo K, Omar S, Kako N, Yasuda S, Sano K, Soehendra N, Moriwaki H. Mediastinal lymph node staging in potentially resectable non-small cell lung cancer: a prospective comparison of CT and EUS/EUS-FNA. Respiration. 2009:78:423-31.

7. Inoue T, Okumura F, Sano H, Mizushima T, Tsukamoto H, Fujita Y, Ibusuki M, Kitano R, Kobayashi Y, Ishii N, et al. Impact of endoscopic ultrasoundguided fine-needle biopsy on the diagnosis of subepithelial tumors: a propensity score-matching analysis. Dig Endosc. 2019;31:156-63.

8. Zhang XC, Li QL, Yu YF, Yao LQ, Xu MD, Zhang YQ, Zhong YS, Chen WF, Zhou PH. Diagnostic efficacy of endoscopic ultrasound-guided needle sampling for upper gastrointestinal subepithelial lesions: a meta-analysis. Surg Endosc. 2016;30:2431-41.

9. Han C, Lin R, Liu J, Hou X, Qian W, Ding Z. Endoscopic ultrasonographyguided biopsy for differentiation of benign and malignant pelvic lesions: a systematic review and meta-analysis. Dig Dis Sci. 2015;60:3771-81.

10. Fernández-Esparrach G, Alberghina N, Subtil JC, Vázquez-Sequeiros E, Florio V, Zozaya F, Araujo I, Ginès A. Endoscopic ultrasound-guided fine needle aspiration is highly accurate for the diagnosis of perirectal recurrence of colorectal cancer. Dis Colon Rectum. 2015:58:469-73.

11. Rzouq F, Brown J, Fan F, Oropeza-Vail M, Sidorenko E, Gilroy R, Esfandyari T, Bonino J, Olyaee M. The utility of lower endoscopic ultrasound-guided 
fine needle aspiration for the diagnosis of benign and malignant pelvic diseases. J Clin Gastoenterol. 2014;48:123-30.

12. Doi S, Yasuda I, Nakashima M, Kawaguchi J, Yamauchi T, Iwashita T, Toda K, Adachi S, Shimizu M, Tsurumi H, et al. Endoscopic ultrasoundguided fine-needle aspiration of lesions near the aortoiliac bifurcation via an upper gastrointestinal approach. J Gastroenterol Hepatol. 2011;26:1717-20.

13. I washita T, Yasuda I, Mukai T, Doi S, Nakashima M, Uemura S, Mabuchi M, Shimizu M, Hatano Y, Hara A, et al. Macroscopic on-site quality evaluation of biopsy specimens to improve the diagnostic accuracy during EUS-guided FNA using a 19-gauge needle for solid lesions: A single-center prospective pilot study (MOSE study). Gastrointest Endosc. 2015:81:177-85.

14. Cotton PB, Eisen GM, Aabakken L, Baron TH, Hutter MM, Jacobson BC, Mergener N, Nemcek A, Petersen BT, Petrini JL, et al. A lexicon for endoscopic adverse events: report of an ASGE workshop. Gastrointest Endosc. 2010;71:446-54.

15. Iwashita T, Nakai Y, Samarasena JB, Park DH, Zhang Z, Gu M, Lee JG, Chang KJ. High single-pass diagnostic yield of a new 25-gauge core biopsy needle for EUS-guided FNA biopsy in solid pancreatic lesions. Gastrointest Endosc. 2013;77:909-15.

16. Chin YK, Iglesias-Garcia J, De La Iglesia D, Lariño-Noia J, Abdulkader-Nallib I, Lázare H, Olmedo SR, Dominguez-Muñoz JE. Accuracy of endoscopic ultrasound-guided tissue acquisition in the evaluation of lymph nodes enlargement in the absence of on-site pathologist. World J Gastroenterol. 2017;23:5755-63.

17. Nishida T, Kawai N, Yamaguchi S, Nishida Y. Submucosal tumors: Comprehensive guide for the diagnosis and therapy of gastrointestinal submucosal tumors. Dig Endosc. 2013;25:479-89.

18. Yasuda I, Tsurumi H, Omar S, Iwashita T, Kojima Y, Yamada T, Sawada M, Takami T, Moriwaki H, Soehendra N. Endoscopic ultrasound-guided fine-needle aspiration biopsy for lymphadenopathy of unknown origin. Endoscopy. 2006;38:919-24.

19. Yasuda I, Goto N, Tsurumi H, Nakashima M, Doi S, Iwashita T, Kanemura N, Kasahara S, Adachi S, Hara T, Shimizu M, Takami T, Moriwaki H.
Endoscopic ultrasound-guided fine needle aspiration biopsy for diagnosis of lymphoproliferative disorders: feasibility of immunohistological, flow cytometric, and cytogenetic assessments. Am J Gastroenterol. 2012;107:397-404.

20. Attili F, Fabbri C, Yasuda I, Fuccio L, Palazzo L, Tarantino I, Dewitt J, Frazzoni L, Rimbaş M, Larghi A. Low diagnostic yield of transduodenal endoscopic ultrasound - guided fine needle biopsy using the 19 - gauge Flex needle: A large multicenter prospective study. Endosc ultrasound. 2017;6:402-8.

21. Bang JY, Kirtane S, Krall K, Navaneethan U, Hawes R, Varadarajulu S. In memoriam: fine-needle aspiration, birth: fine-needle biopsy: the changing trend in endoscopic ultrasound-guided tissue acquisition. Dig Endosc. 2019;31:197-202.

22. Iwashita T. Endoscopic ultrasound-guided tissue acquisition : can fork and crown cut the tissue ? Dig Endosc. 2019;31:146-7.

23. Kovacevic B, Vilmann P. EUS tissue acquisition: from A to B. Endosc Ultrasound. 2020;9:225-31.

24. Mita N, Iwashita T, Uemura S, Iwasa Y, Toda K, Mukai T. Endoscopic ultrasound - guided fine needle biopsy using 22 - gauge franseen needle for the histological diagnosis of solid lesions : a multicenter prospective pilot study. Dig Dis Sci. 2019;65:1155-63.

25. Larghi A, Ibrahim M, Fuccio L, Lekkerkerker S, Eisendrath P, Frazzoni L, Fockens P, Marca ML, van Hooft JE, Deviere J, Costamagna G. Forwardviewing echoendoscope versus standard echoendoscope for endoscopic ultrasound-guided tissue acquisition of solid lesions: a randomized, multicenter study. Endoscopy. 2019;51:444-51.

26. Thinrungroj N, Hara K, Mizuno N, Kuwahara T, Okuno N. Utility of forwardview echoendoscopy for transcolonic fine- needle aspiration of extracoIonic lesions : an institutional experience. Clin Endosc. 2020;53:60-4.

\section{Publisher's Note}

Springer Nature remains neutral with regard to jurisdictional claims in published maps and institutional affiliations.
Ready to submit your research? Choose BMC and benefit from:

- fast, convenient online submission

- thorough peer review by experienced researchers in your field

- rapid publication on acceptance

- support for research data, including large and complex data types

- gold Open Access which fosters wider collaboration and increased citations

- maximum visibility for your research: over 100M website views per year

At BMC, research is always in progress.

Learn more biomedcentral.com/submissions 